\title{
El cómic underground y su relación con el lowbrow art. \\ Underground comic and its relation with lowbrow art.
}

\author{
Sonia Puga García \\ Departamento de Dibujo \\ Universidad de Granada, \\ España \\ soniactica@gmail.com
}

\author{
Recibido 30/05/2017 Revisado 09/06/2017 \\ Aceptado 19/06/2017 Publicado 01/07/2017
}

\section{RESUMEN}

El arte lowbrow y el cómic underground guardan muchas similitudes. Ambos estaban creados por una juventud cansada de la sociedad en que vivían a la cual criticaban con un toque irónico.

Los artistas lowbrow estuvieron influidos desde su infancia por los cómics, que sufrieron la censura en una época en la que la sociedad era muy puritana.

Ni grandes editoriales, ni museos, ni galerías de arte elitistas apostaron por ellos, pero se ganaron un sitio en el mundo del arte gracias a su mensaje revolucionario que rompía con todo lo que se venía haciendo hasta ahora.
ABSTRACT

Lowbrow art and underground comics have many similarities. Both were created by young people tired of the society in which they lived and they criticized it with a hint of irony.

Lowbrow artists were influenced by comics in their childhood, which suffered censorship at a time when the society was very puritan.

No big publishers, no museums, no elitist art galleries bet on them, but they gained a place in the art world thanks to its revolutionary message that broke with everything that had been done so far.

\section{Sugerencia para citar este artículo}

Puga Garcia, S. (2017). El cómic underground y su relación con el lowbrow art. Tercio Creciente, 12, págs. 29-38. DOI: 10.17561/rtc.n12.3 
DOI: $10.17561 /$ rtc.n12.3

Estudio
http://revistaselectronicas.ujaen.es/index.php/RTC/index www.terciocreciente.com

Palabras clave / Keywords

Cómic, cómix, underground, Lowbrow Art.

\section{Sugerencia para citar este artículo}

Puga Garcia, S. (2017). El cómic underground y su relación con el lowbrow art. Tercio Creciente, 12, págs. 29-38. DOI: 10.17561/rtc.n12.3 


\section{El cómic underground y su relación con el lowbrow art.}

\section{Introducción:}

Mucho se está hablando últimamente de un movimiento artístico que se originó en California llamado lowbrow o Surrealismo Pop, especialmente desde que en diciembre de 2016 el Centro de Arte Contemporáneo de Málaga acogiera la exposición de la obra de Mark Ryden, uno de los máximos exponentes de dicha corriente.

El movimiento lowbrow es fruto de la influencia de otras manifestaciones como el grafiti, el surf, el tatuaje, el arte erótico, el hot rod o la cultura tiki entre otros. En este trabajo queremos destacar la importancia que tuvo el cómic y el cómic underground en el nacimiento del lowbrow.

\section{El cómic y el cómix underground}

A final de los sesenta nace el cómic underground, un tipo de cómic que se aleja de las grandes editoriales para apostar por las independientes, trata temas marginales, denuncia a la sociedad del momento y conoció su máxima expansión en los años setenta.

Las dos grandes editoriales de los sesenta eran Marvel y DC, los cómics underground desde un comienzo rechazaron los mainstream para optar por la autoedición o por editoriales independientes.

El cómix underground se originó en San Francisco y uno de sus fundadores fue Robert Crumb (Celis, 2016). Junto a él Gilbert Shelton, Vaughn Bodé, Justin Green, ‘Spain’ Rodriguez o Victor Moscoso fueron los creadores de historietas principales de esta nueva vertiente. Nacía así una generación de dibujantes de cómic que pretendían expresar libremente lo que pensaban mediante sus dibujos, gracias a este grupo de artistas cuyo líder era Crumb, el lenguaje del cómic sufrió un cambio que ha llegado hasta nuestros días.

Crumb nació en Pensilvania pero se trasladó a San Francisco donde creó el fanzine Zap Cómix que comenzó como un comicbook y seguía el movimiento contracultural de una juventud muy cansada de la sociedad en la que vivían. Esta publicación fue la que popularizó el término cómix, con el cual se designaba a este nuevo tipo de cómic para diferenciarlo del anterior. No se tiene muy claro cual es el origen, pero se piensa que la " $x$ " hacía referencia a la clasificación del mismo x-rated que significa "pornográfico" o "no apto para menores”. Zap Cómix tuvo numerosas denuncias por los temas que trataba como la política y el sexo, por aquel entonces muy revolucionarios ya que en Estados Unidos los cómics estaban principalmente dirigidos a niños y a jóvenes. En ella apareció por primera vez El Gato Fritz, personaje creado por el propio Crumb que protagonizaba historietas que reflejaban lo que la sociedad del momento vivía. Era un personaje que se alejaba de la belleza y de una conducta normal, más bien era todo lo contrario, se dedicaba al consumo de alcohol y drogas o a la práctica desenfrenada del sexo. Su autor no soportó la fama que consiguió este personaje y en uno de los capítulos de sus historietas le mató. Otros de sus personajes más conocidos son Mr. Natural, Flakey Foont, Angelfood McSpade y Schuman the Human. Crumb ganó mucha popularidad, llegó a diseñar portadas de discos de algunos de los grupos de rock más importantes del momento (Longui, 1995).

Gilbert Shelton fue pionero al crear a un personaje con el que parodió a los superhéroes, 
DOI: $10.17561 /$ rtc.n12.3

Estudio
http://revistaselectronicas.ujaen.es/index.php/RTC/index www.terciocreciente.com se trata de Wonder Warthog, que en español se tradujo como "El Superserdo" (FIG. 1). Era un jabalí con superpoderes y lleno de verrugas que al igual que Superman se escondía detrás de la identidad de un periodista muy aburrido que trabajaba para el periódico "El miope matutino". También creó algunas historietas como "el gato de Fat Freddy" o los "Fabulosos Freak Brothers", tres hermanos hippies consumidores de drogas y aficionados a buscar problemas (Fernández, 2010).

Justin Green fue conocido por ser el creador de las novelas gráficas autobiográficas y por sus duras críticas hacia la iglesia Católica. En su historieta "Binky Brown conoce a la Virgen María” él mismo es el protagonista, y aparecía como un adolescente que mostraba los problemas propias de esa edad pero contados con cierta dureza para determinados públicos, ya que una de las preocupaciones de este

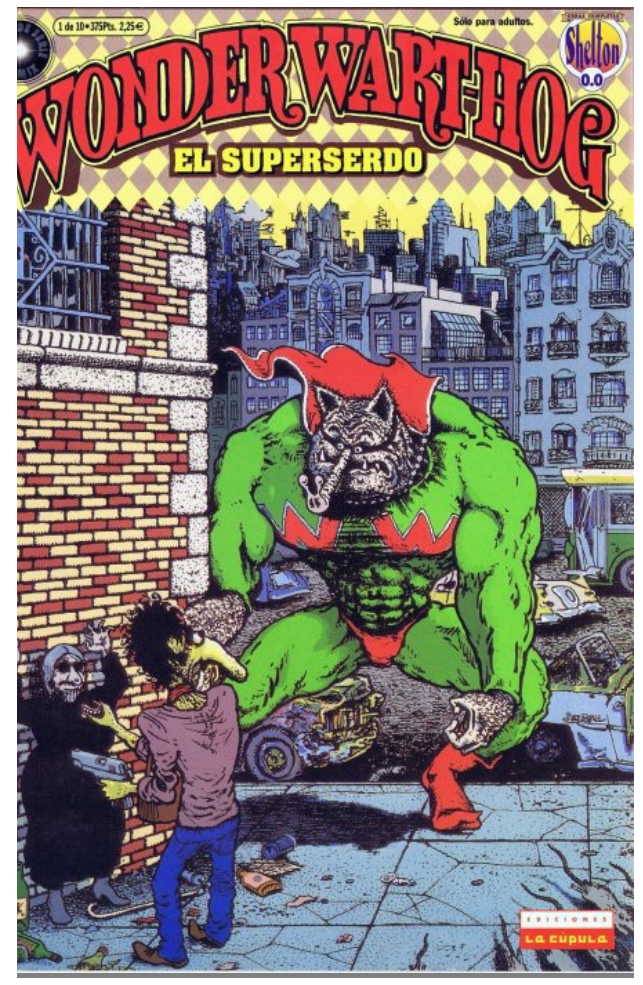

álter ego de Justin Green era el rayo de luz que salía de sus genitales. La historieta fue pionera también en cuanto a duración, los comic-book constaban normalmente de unas veintidós páginas, y esta se alargaba hasta llegar a las cuarenta y cuatro, algo que nunca nadie había hecho en este campo.

A España también llegó el cómic underground. Con formatos sobre todo autoeditados entre los que destacan "El Rollo enmascarado", "Paupérrimus Comixy" y "Catalina”. También podemos destacar dentro de las publicaciones dedicadas a los cómics alternativos la revista "El Víbora" que tenía como lema "Cómix para supervivientes” y que no solo se dedicó a publicar a dibujantes españoles sino que entre sus páginas encontrábamos a algunos de los grandes de Estados Unidos como Robert Crumb y Gilbert Shelton.
"El Superserdo" (FIG. 1).

wonder Wart- Hog. Fotografia de www.nmia.com 


\section{Qué es el movimiento lowbrow y cual es su relación con el cómic underground.}

El lowbrow es una corriente artística que nació por la unión entre diferentes hechos de la vida cotidiana que sucedían en las calles de Estados Unidos, concretamente en California. Personas muy diferentes como amantes de las motocicletas y coches customizados, surfistas, skaters, hippies, dibujantes de cómic y muchos otros que tenían como principio alejarse de las normas y seguir las propias suyas, en general los que iban en contra del sistema, venían a contrastar con la sociedad conservadora y el ideal de familia tradicional americana.

Más adelante esta corriente tendría nuevas fuentes de inspiración con la aparición de figuras como los grafiteros, los tatuadores o los punks. Como dijo Anthony Ausgang en una entrevista para la revista "Wow x Wow", el lowbrow está inspirado en muchas manifestaciones de la low culture, es decir, cultura inferior o de baja categoría (WOW X WOW, 2014).

Se trata de un arte en el que muchos artistas plasman sus ideales y sus pensamientos que en la mayoría de los casos eran muy revolucionarios, se revelan contra el arte existente y cuestionan
FIG. 2. Mark Ryden -

Fotografía de www. http://markryden.com/ sus principios, creaban obras provocadoras que causaban polémicas considerables en aquella época. Muchos trataban de expresar sus sentimientos, sus miedos, su visión de la vida, burlándose de los referentes como la televisión, el consumismo, el cine, en general de la sociedad.

Este movimiento nace en movimientos callejeros de Los Angeles a partir de los años setenta, y se le conoce por varios nombres lowbrow, arte underground o surrealismo pop. Las obras de esta corriente mezclan creaciones absurdas próximas al surrealismo con carácter sarcástico, e imágenes de la cultura popular relacionadas con la publicidad o la cultura de masas. Los artistas tratan los temas de manera irónica, y a pesar de que muchas de las obras son provocadoras y vanguardistas, están realizadas con técnicas clásicas como óleo, como las pinturas de Mark Ryden que estuvo profundamente influenciado por los maestros de la pintura clásica. (FIG. 2)

Muchos de los cómics underground tratan también temas de actualidad de manera sarcástica haciendo una crítica a la sociedad Celdrán, H. (2012)..

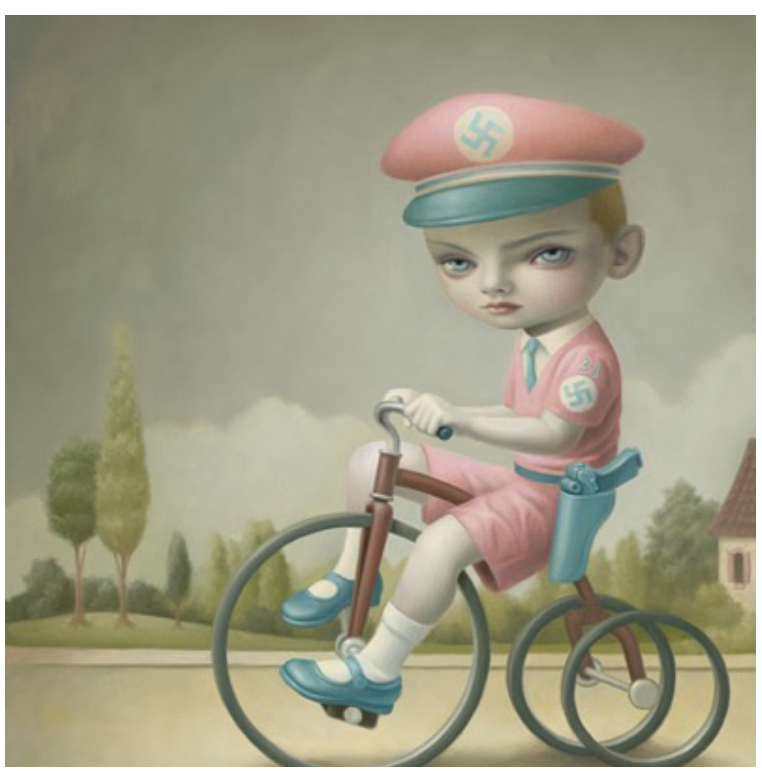


DOI: $10.17561 /$ rtc.n12.3

Estudio
http://revistaselectronicas.ujaen.es/index.php/RTC/index www.terciocreciente.com

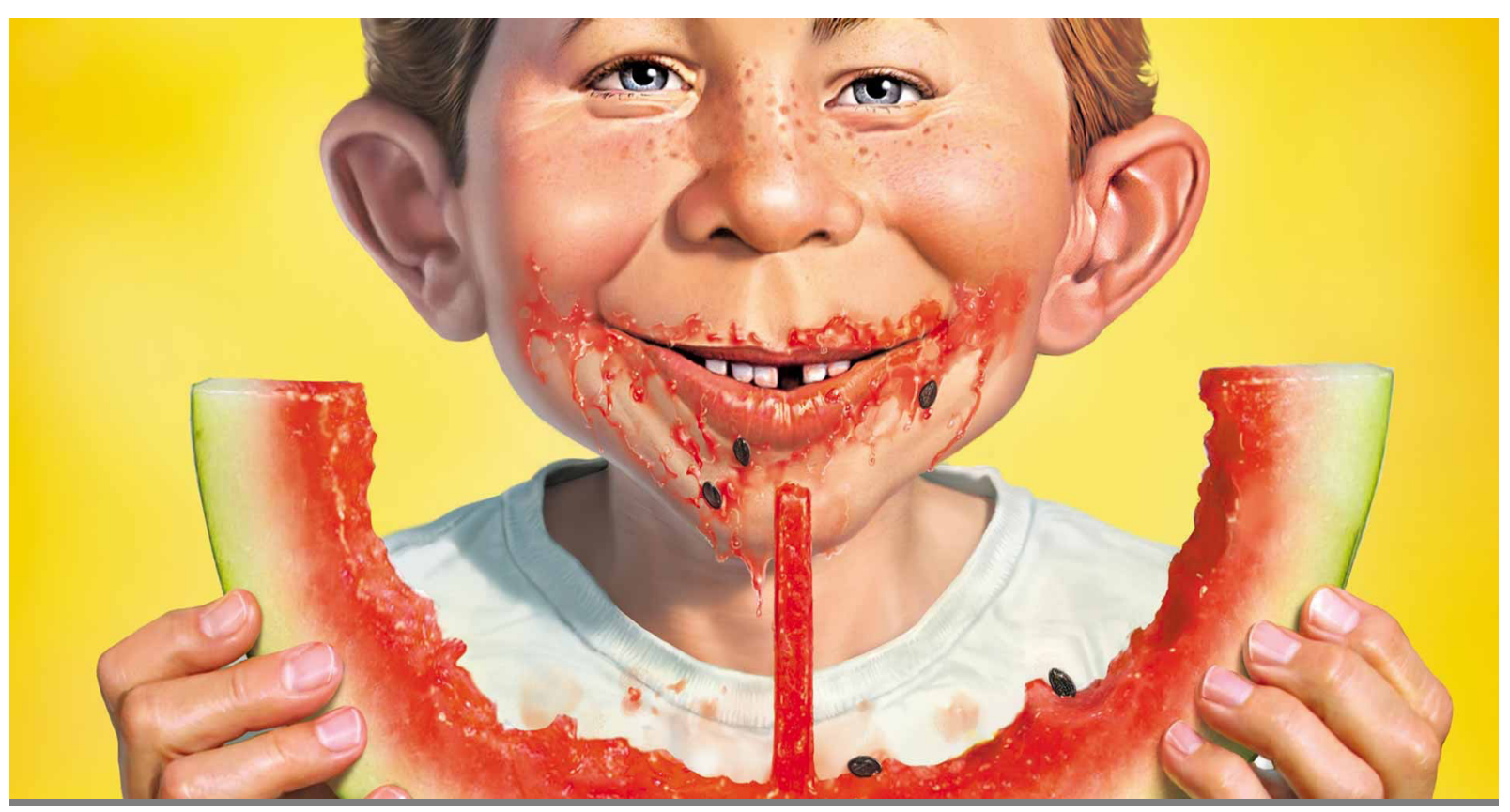

FIG. 3. Alfred Newman

Fotografía de www.madmagazine.com/

Alfred Newman fue el protagonista de las portadas de la revista MAD

Una característica importante del lowbrow es la autogestión, los mismos artistas se marcaban sus objetivos y se encargaban de realizar la obras y promocionarlas, se mostraban en espacios alternativos y además se reproducían masivamente mediante impresión de pósters, catálogos, o fanzines. Este es un rasgo común con los cómics underground cuyos autores se autopublicaban dejando de lado a las grandes editoriales.

Desde el principio se trató a esta corriente del lowbrow con menosprecio, nunca tuvo gran interés en el mundo del arte y esto vino motivado porque el mundo de las Bellas Artes no lo consideraba con suficiente categoría como para adentrarse en las altas esferas artísticas, pero poco a poco consiguió ganarse un espacio entre las grandes galerías.

Aunque esta corriente empezó en Estados Unidos pronto se extendió a todo el mundo, de hecho en muchos países tuvieron artistas que influidos por lo que vivían en su entorno presentaban sus propias peculiaridades y formaron parte de una escena característica de ese país. Podemos destacar Japón, Inglaterra, Francia, México, Chile o Perú entre otros. 
El lowbrow engloba diferentes manifestaciones del arte como el grafiti, el cómic, la ilustración o la pintura. Su estética además combina con la del tatuaje, de los cartoons clásicos, del cómic underground, el hot rod, el surf o el grafiti entre otros.

A muchos de los artistas de esta corriente no les gustaba precisamente que les encasillaran o englobaran en este grupo ni que les pusieran etiquetas ya que trabajaban de modo individual y cada uno defendía que su arte es único. Si observamos las obras de los artistas de la cultura lowbrow podemos comprobar que cada uno tiene un estilo propio muy definido que nada tiene que ver entre ellos, además no encontraban el sentido a poner un nombre a algo que ya lo tenía previamente, con esto se limitaba su arte y era en muchas ocasiones inapropiado.

Podíamos encontrar dos grupos de artistas, los que aceptaban el término lowbrow para definir su arte que se relacionaban con lo opuesto a la élite, con una actitud rebelde y revolucionaria en contra de las normas, y por otro lado estaban los que rechazaban esta etiqueta y simplemente querían hacer arte. Los primeros estaban más influenciados por la estética del cómix underground y su obra personal se centraba más en la realización de retratos con una historia a su alrededor, elementos simbólicos y representativos del retratado. Los segundos sin embargo estaban influenciados por un rango más amplio de movimientos y estilos y sus obras siempre estaban centradas en torno a una temática. Ambos grupos tenían en común que realizaban pinturas narrativas y además sus influencias eran similares, como el nacimiento de la cultura punk en los años setenta, el dadaísmo, el surrealismo, el Outsider art, las pin ups, las películas de serie B, la animación, el cómic, el mundo Disney, el grafiti, la cultura urbana, la ilustración o el cómix underground (Hispano, 2012).
Pero de todas estas manifestaciones y corrientes, sin duda lo que más ha influenciado a artistas lowbrow han sido los cartoons bien sean del mundo Disney o los trabajos creados por Robert Crumb y los artistas que dieron vida a la revista MAD (FIG.3). De hecho muchos de ellos comenzaron trabajando dibujando cómics underground o en dibujos animados que se salían un poco de lo común, como Ren \& Stimpy.

El lowbrow tenía al igual que el cómic underground un fuerte sentido de la sátira, ambos creaban obras que se liberaban de los ideales clásicos de belleza.

Conforme Robert Williams se hacía adolescente comenzó a interesarse por Los cuentos de la cripta, La bóveda del horror y la revista MAD entre otros cómics de la editorial EC. Los autores de esta editorial fueron una gran influencia para él, pero cabe destacar la figura de Basil Wolverton que publicó en la Marvel y en la revista MAD. Su característica más peculiar era el modo en que deformaba los personajes en cuanto a anatomía se refiere, narices retorcidas que adoptaban diferentes formas, ojos saltones como los de un caracol, todo esto llamó enormemente la atención de Williams y en sus creaciones se puede ver una gran influencia de estas criaturas extrañas de Wolverton, así fue como aprendió a ganar libertad en cuanto a la creación de personajes rompiendo las normas y cánones establecidos llegando a una especie de mutación humana, además de centrarse en esas temáticas tan provocadoras que rompían con la moral de aquella época. Williams ya realizaba dibujos para cómic desde que era estudiante hasta que decidió enviar sus trabajos a Robert Crumb, creador de Zap Comix, y comenzó a trabajar como dibujante para esta publicación (Campion, 2015)..

Las pinturas de la californiana Camille Rose 
DOI: $10.17561 /$ rtc.n12.3

Estudio
http://revistaselectronicas.ujaen.es/index.php/RTC/index www.terciocreciente.com
Garcia hacen referencia a toda las cosas que le han influenciado en su vida, como los cómics. Tras sus estudios se sumergió en el mundo del cómic underground en San Francisco hasta el punto de que durante dos años dejó de pintar. Robert Crumb fue una gran influencia para ella y se nota en los personajes que pinta, que parecen salidos de un mundo oscuro y malévolo.

Una de las primeras fuentes de inspiración de Gary Baseman fue la revista MAD. En sus inicios en el mundo del arte de dedicaba al cómic hasta que amplió su arte a otros campos muy variados, pero en sus personajes siempre se ve la influencia de las historietas.

Todd Schorr por su parte también estuvo profundamente influenciado por gran cantidad de cosas como las pinturas de Salvador Dalí y los cómics underground de los años cincuenta como MAD. Un rasgo muy característico de sus pinturas es que tienen un fuerte carácter narrativo, un rasgo común que comparte con el cómic al igual que lo hacen muchas de las obras de otros artistas lowbrow. Mark Ryden, su esposa Marion Peck, Alex Gross, Robert Williams o Shag entre otros presentan también ese carácter narrativo, sus obras cuentan historias y bien podrían ser una viñeta 0 portada de cómic. Todos ellos estuvieron influenciados por los cómic books (Barnes, 2014).

Por otro lado tenemos a Rick Griffin cuya obra nada tiene que ver con los anteriores.

FIG. 4. Rick Griffin - Murphy.

Fotografía de http://www.myraltis.co.uk/rickgriffin/
Fue un artista muy conocido por sus diseños de carteles en el mundo de la psicodelia de San Francisco, pero también trabajó en el mundo del cómic ${ }^{1}$ (Stephenson, n.d.a\&b).. Realizó una tira de dibujos animados que se publicó en el segundo número de la revista Surfer Magazine (FIG.4), para la cual estuvo trabajando intermitentemente a lo largo de su corta pero intensa vida. También realizó numerosos dibujos para la revista clandestina Zap Comix cuando vivió en San francisco. Sus cómics siempre tuvieron un toque humorístico, y para ellos diseñó personajes que fueron protagonistas de escenas de surf con unos trazos simples y coloridos y con un lado un tanto infantil.

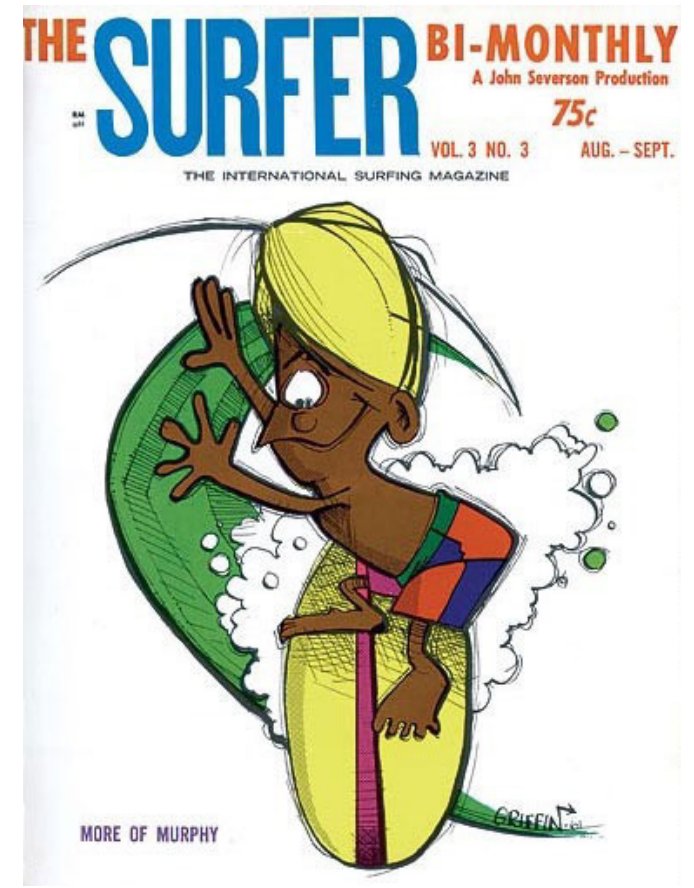

1. Stephenson, T. (n.d.). Griffin tuvo idas y venidas en el mundo del cómic. Se dedicaba al arte de los carteles en plena explosión de la cultura psicodélica en San Francisco, pero en los setenta se convirtió al Cristianismo y su trabajo dio un cambio radical. Comenzó a realizar ilustraciones para portadas de libros y disco religiosos. 


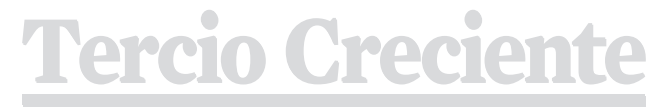

DOI: $10.17561 /$ rtc.n12.3

Estudio

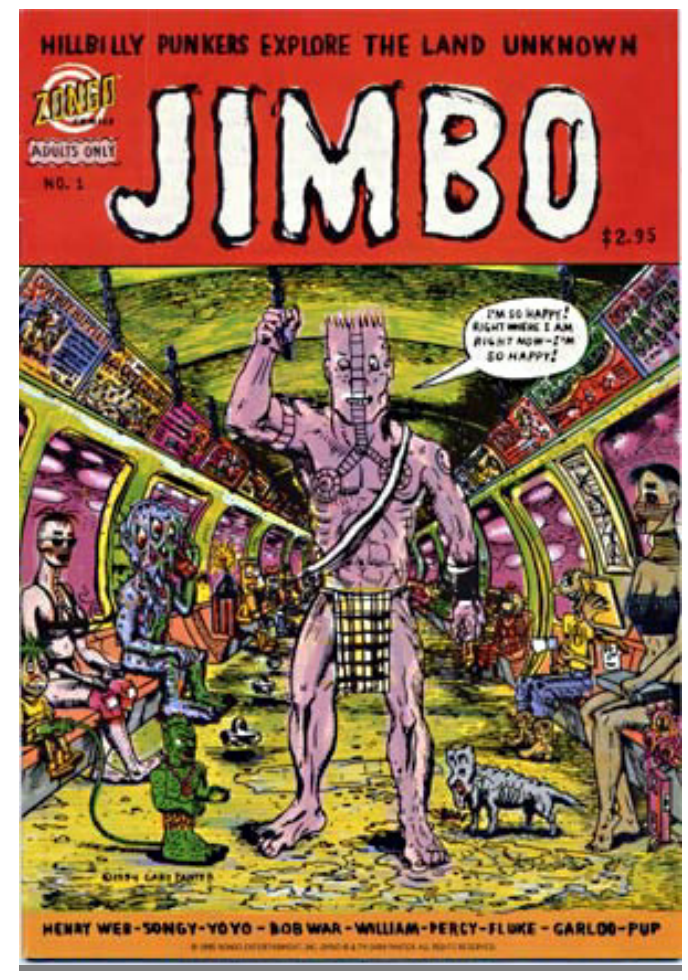

(FIG.5) Jimbo.Jimbo No. 1 Zongo Comics, 1995

Gary Panter fue un incomprendido por la gente de su entorno al tener como fuente de inspiración a artistas tan provocadores como Ed Roth o Basil Wolverton. Se dedicó a múltiples disciplinas y cuando en 1977 se marchó a Los Angeles comenzó a trabajar en diferentes campos artísticos entre los que destaca el cómic, creó un personaje de cómic bastante peculiar, Jimbo, su álter ego. Publicó sus historietas en la revista punk Slash y además llevó sus cómic publicados por el mismo a tiendas de ropa y a Soap Plant ${ }^{2}$ (Hart, 2011). Colaboró con la serie del personaje de cómic "Pee-Wee Herman" y en 2006 participó en la exposición itinerante "American Comics" junto a otros artistas como Robert Crumb.
Revista de Estudios en Sociedad, Artes y Gestión Cultural

http://revistaselectronicas.ujaen.es/index.php/RTC/index www.terciocreciente.com

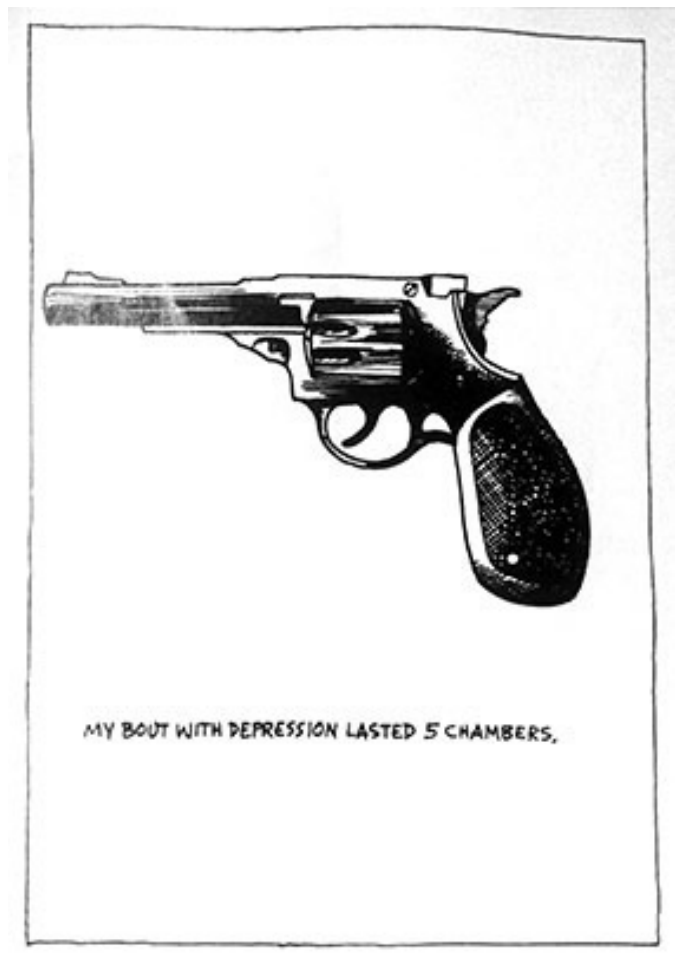

(FIG.6) Raymond Pettibon. (2000) Juxtapoz, n²4, p.64

Raymond Pettibon comenzó a dibujar habitualmente con doce años y desde que era estudiante comenzó a publicar sus propios fanzines. Sus primeros trabajos eran una sátira de la política. Sus dibujos a base de trazos negros muy simples realizados en tinta y dejando el fondo blanco junto con algunas frases que incluía tenían una gran fuerza comunicativa y cuya estética recordaba a las viñetas del cómic (FIG. 6). En ocasiones utiliza personajes de dibujos americanos como el Gato Félix y los transforma en otros elementos para darles un significado.

2. Hart, H. (2011). Soap Plant comenzó como un negocio familiar en el barrio de Los Feliz y su éxito permitió la apertura en el mismo local de un espacio expositivo llamado La Luz de Jesus, la galería por excelencia del arte Lowbrow. Desde ella se propulsó la carrera de muchos artistas que comenzaban a dar forma a esta corriente artística. 


\section{Referencias}

Barnes, B. (2014). Mark Ryden: Drawing a Dividing Line. Disponible en línea: https://www.nytimes. com/2014/05/18/fashion/mark-ryden-drawing-a-dividing-line.html?_r=2

Campion, C. (2015). Robert Williams: 'My stuff is way kitsch - to an abstract level'. Disponible en línea: https://www.theguardian.com/artanddesign/2015/apr/01/artist-robert-williams-appetite-fordestruction-slang-aesthetics

Celdrán, H. (2012). Alex Gross pinta un mundo 'espiritualmente profundo y culturalmente insípido' Disponible en línea: http://www.20minutos.es/noticia/1318748/0/alex-gross/pintura/mundoinsipido/

Celis, B. (2016). Crumb es considerado "leyenda viva del cómic underground, responsable de clásicos de la historieta como Mr. Natural y Fritz el Gato, además de maestro del tebeo autobiográfico"

Fernández, L. (2010). A final de los años sesenta, cuando se producía la explosión de la psicodelia y la cultura hippie, Shelton se hizo famoso, y aunque historietas como las de los "Freak Brothers" fueron de gran éxito nunca tuvieron el mismo nivel que las de Crumb.

Hart, H. (2011). La Luz de Jesus Gallery marks 25 years of underground art. Disponible en línea: http://articles.latimes.com/2011/nov/18/entertainment/la-et-la-luz-20111118

Hispano, A. (2012). Mark Ryden, surrealismo pop, arte 'freak'. Disponible en línea: http://www. lavanguardia.com/cultura/20120222/54257862698/mark-ryden-surrealismo-pop-arte-freak.html

Kennerly, S. (1996). Raymond Pettibon. Juxtapoz, 2(3).

Longui, J. (1995). Crumb asegura que todos estos personajes salían de sus viajes con el LSD, los veía a cada uno de ellos cuando consumía esta sustancia.

Stephenson, T. (n.d.a). Rick Griffin Biography. Disponible en línea: http://www.myraltis.co.uk/ rickgriffin/bio.htm

Stephenson, T. (n.d.b). Rick Griffin | COTW Surf Artist. Disponible en línea: http://www. clubofthewaves.com/surf-artist/rick-griffin.php

WOW X WOW. (2014). Anthony Ausgang - Artist Interview - WOW x WOW. Disponible en línea: https://wowxwow.com/artist-interview/anthony-ausgang-ai 